\title{
IMPLEMENTASI JAVA NETBEANS DAN DATABASE MySQL DALAM PENGOLAHAN DATA NILAI SISWA SMP NEGERI 24 PADANG
}

\author{
Willyansah \\ Akademi Manajemen Informatika \& Komputer (AMIK) Tri Dharma Pekanbaru \\ Jalan Jendral Sudirman No. 68, Pekanbaru - Riau \\ e-mail : wilyerta@gmail.com
}

\begin{abstract}
ABSTRAK
Kemajuan teknologi yang semakin pesat sangat mempengaruhi manusia secara tidak langsung. Komputer sebagai salah satu hasil kemajuan teknologi dapat membantu manusia dalam meningkatkan kualitas dan kuantitas kerja karyawan. Kemajuan teknologi saat ini dapat membantu dalam pengolahan data, dimana pada kenyataan ini komputer sangat diperlukan, mengingat data yang dibutuhkan memerlukan format dan laporan yang baik dan tepat. Pada SMP Negeri 24 Padang, pengolahan data siswa masih dilakukan secara manual, sehingga penyajian informasi membutuhkan waktu yang lama, dan kinerja staff sekolah belum optimal. Sistem ini pengolahan data nilai siswa ini mampu membantu memberikan informasi yang lebih cepat, tepat dan akurat kepada user dan juga mampu mengelola data secara maksimal dan praktis.
\end{abstract}

Kata kunci : Pengolahan Nilai, sistem informasi, Java Netbeans, Raport.

\begin{abstract}
Fast technological progress progessively very is influencing of human being indirectly. Computer as one of the result of technological progress can assist human being in improving amount and quality work employees. Current technological advances can help to processing the data, which the need of a computer is necessary, knowing that the required data formats and reports need to be a good and proper reports. At SMP Negeri 24 Padang, student data processing is still done manually, so the presentation of information takes a long time, and the performance of school staff is not optimal. This system is able to help provide information more quickly, precisely and accurately to the user and is also able to manage data optimally and practically
\end{abstract}

Keywords : Value Processing, Infomation Systems, Java Net Beans, Raport.

\section{PENDAHULUAN}

Teknologi Informasi memberikan perubahan dalam tatanan hidup sebagian masyarakat yang ada di Dunia Khususnya Indonesia. Informasi yang datang secara cepat dan terjangkau memberikan kemudahan bagi pengguna internet mendapatkan informasi apapun yang mereka butuhkan. Sistem informasi memudahkan seseorang dalam berkomunikasi dengan orang lain, tak terkecuali dalam pengiriman data. Teknologi Informasi yang membentuk Sistem Informasi memberikan efek positif kepada pekerja khususnya mereka yang berkecimpung dalam dunia IT itu sendiri.

Sistem informasi sudah menjangkau ke semua bidang, baik itu dari segi industri maupun dalam dunia pendidikan. Dalam dunia pendidikan, dibutuhkan sistem informasi yang praktis dan friendly agar proses belajar mengajar menjadi lebih mudah dan cepat. Sekolah menengah negeri 24 Padang masih menggunakan microsoft excel dalam mengolah data sehingga mengakibatkan kurang optimalnya kinerja komputer. Dengan jumlah data yang banyak, akan sangat lama untuk memproses nilai siswa, sehingga sering membutuhkan waktu yang lama untuk mendapatkan hasil nilai siswa.

Untuk memberikan kemudahan dalam pembuatan sistem informasi ini dibentuk lah beberapa Rumusan masalah yang di dapat setelah adanya observasi langsung ke instansi terkait, dimana diantaranya adalah sebagai berikut : 
IN F ORMA TIK

Jurnal Informatika, Manajemen dan Komputer, Vol.11 No.2, Desember 2019

eISSN : 2580-3042

pISSN : 1979-0694

1. Bagaimana membuat sebuah sistem informasi yang mudah digunakan dan mempercepat penilaian tanpa harus menghitung nilai secara satu persatu?

2. Bagaimana mengatur Database MySQL agar mampu menampung data dalam jumlah besar, tanpa khawatir akan kehilangan data siswa dan alumni.

3. Bagaimana membuat sistem informasi yang cepat dan efisien terhadap waktu?

\section{METODOLOGI PENELITIAN}

Banyak model yang telah dikembangkan untuk membantu proses pengembangan perangkat lunak. Model-model ini pada umumnya mengacu pada model proses pengembangan sistem yang disebut System Development Life Cycle (SDLC). Mari kita perhatikan Gambar berikut ini :

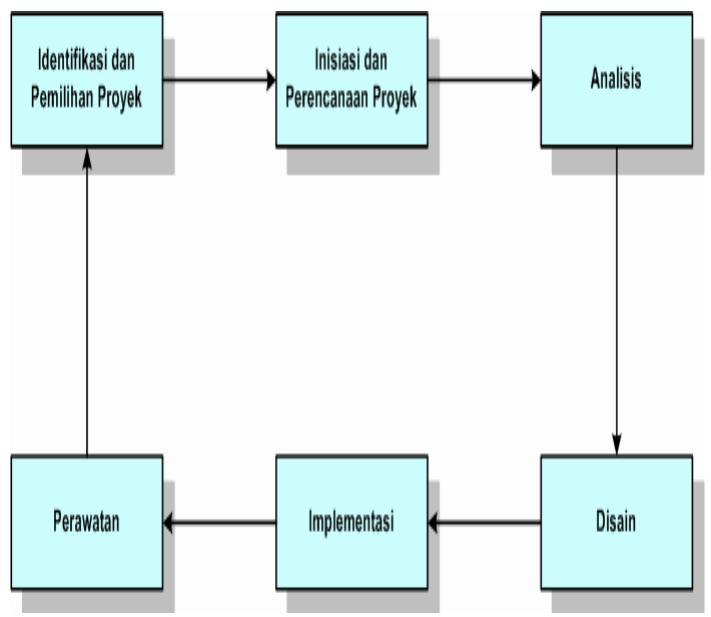

Gambar 1. System Development Life Cycle (SDLC)

Sumber : Rekayasa Perangkat Lunak (Pressman, 2015)

Setiap model yang dikembangkan mempunyai karakteristik sendiri-sendiri. Namun secara umum ada persamaan dari model-model ini, yaitu :

1. Kebutuhan terhadap definisi masalah yang jelas. Input utama dari setiap pengembangan perangkat lunak adalah pendefinisian masalah yang jelas. Semakin jelas akan semakin baik karena akan memudahkan dalam penyelesaian masalah.

2. Tahapan-tahapan pengembangan yang teratur. Meskipun model-model perangkat lunak memiliki pola yang berbeda beda, biasanya model-model tersebut mengikuti

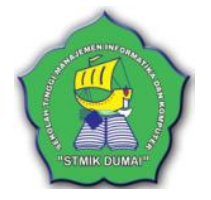

pola umum analysis $\rightarrow$ design $\rightarrow$ coding $\rightarrow$ testing $\rightarrow$ maintenance.

3. Stakeholder berperan sangat penting dalam keseluruhan tahapan pengembangan. Stakeholder dalam rekayasa perangkat lunak dapat berupa pengguna, pemilik, pengembang, pemrogram dan orang-orang yang terlibat dalam rekayasa perangkat lunak tersebut.

4. Dokumentasi bagian penting dari pengembangan perangkat lunak. Masingmasing tahapan dalam model biasanya menghasilkan sejumlah tulisan, diagram, gambar atau bentuk-bentuk lain yang harus didokumentasikan dan merupakan bagian tak terpisahkan dari perangkat lunak yang dihasilkan.

5. Keluaran dari proses pengembangan perangkat lunak harus bernilai ekonomis. Nilai dari sebuah perangkat lunak sebenarnya agak susah di-rupiah-kan. Namun efek dari penggunaan perangkat lunak yang telah dikembangkan haruslah memberi nilai tambah bagi organisasi. Hal ini dapat berupa penurunan biaya operasi, efisiensi penggunaan sumberdaya, peningkatan keuntungan organisasi, peningkatan "image" organisasi dan lainlain.

Model siklus hidup (life cycle model) adalah model utama dan dasar dari banyak model. Salah satu banyak model yang cukup dikenal dalam dunia rekayasa perangkat lunak adalah model The Waterfall Model. Disebut waterfall (air terjun) karena memang diagram tahapan prosesnya mirip dengan air terjun yang bertingkat. Secara umum tahapan pada model waterfall dapat dilihat pada gambar 2 berikut:

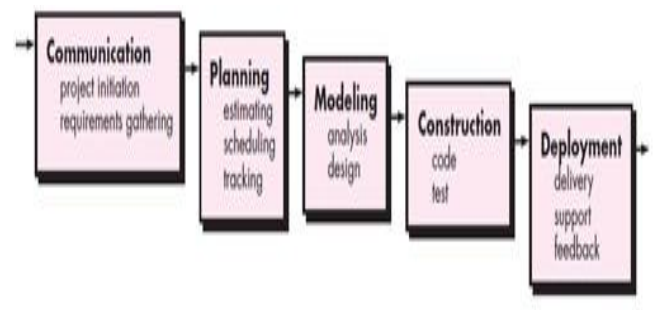

Gambar 2. Model Waterfalll

Sumber : Rekayasa Perangkat Lunak (Pressman, 2015) 
IN F O R M A I I A

Jurnal Informatika, Manajemen dan Komputer, Vol.11 No.2, Desember 2019

eISSN : 2580-3042

pISSN : 1979-0694

Tahapan-tahapan dalam The Waterfall Model secara ringkas adalah:

a. Tahap investigasi dilakukan untuk menentukan apakah terjadi suatu masalah atau adakah peluang suatu system informasi dikembangkan.

b. Tahap analisis bertujuan untuk mencari kebutuhan pengguna dan organisasi serta menganalisa kondisi yang ada (sebelum diterapkan sistem informasi yang baru).

c. Tahap disain bertujuan menentukan spesifikasidetil dari komponen system informasi (manusia, hardwere, softwere, network dan data) dan produk-produk informasi yang sesuai dengan hasil tahapan analisi.

d. Tahapan implementasi merupakan tahapan untuk mendapatkan atau mengembangkan hardwere (pengkodean program), melakukan pengujian, pelatihan dan perpindahan ke system baru.

e. Tahapan perawatan (maintenance) dilakukan ketika system informasi sudah dioperasikan. Pada tahapan ini dilakukan monitoring proses, evaluasi dan perubahan (perbaikan) bila diperluka

\section{HASIL DAN PEMBAHASAN}

Setelah mengidentifikasi permasalahan dari pengolahan data yang ada saat sekarang di SMP N 24 Padang dan di lanjutkan dengan memjabarkan point-point dari perumusan masalah maka penulis menjelaskan proses pembuatan alur sistem yang akan di buat nanti, yang di mulai dari Alisan sistem informasi lama. Selanjutnya dibuatlah aliran sistem informasi baru, yang memberikan solusi untuk kelemahan dari proses pengolahan data yang sedang berlangsung.

\section{a. Aliran Sistem Informasi Lama}

Aliran sistem informasi lama memberikan gambaran Bagaimana proses pengolahan data yang sedang berjalan di SMP Negeri 24 Padang, berikut ini merupakan tampilan dari diagram aliran sistem informasi. 
IN F ORMA T I K A

Jurnal Informatika, Manajemen dan Komputer, Vol.11 No.2, Desember 2019

eISSN : 2580-3042

pISSN : 1979-0694

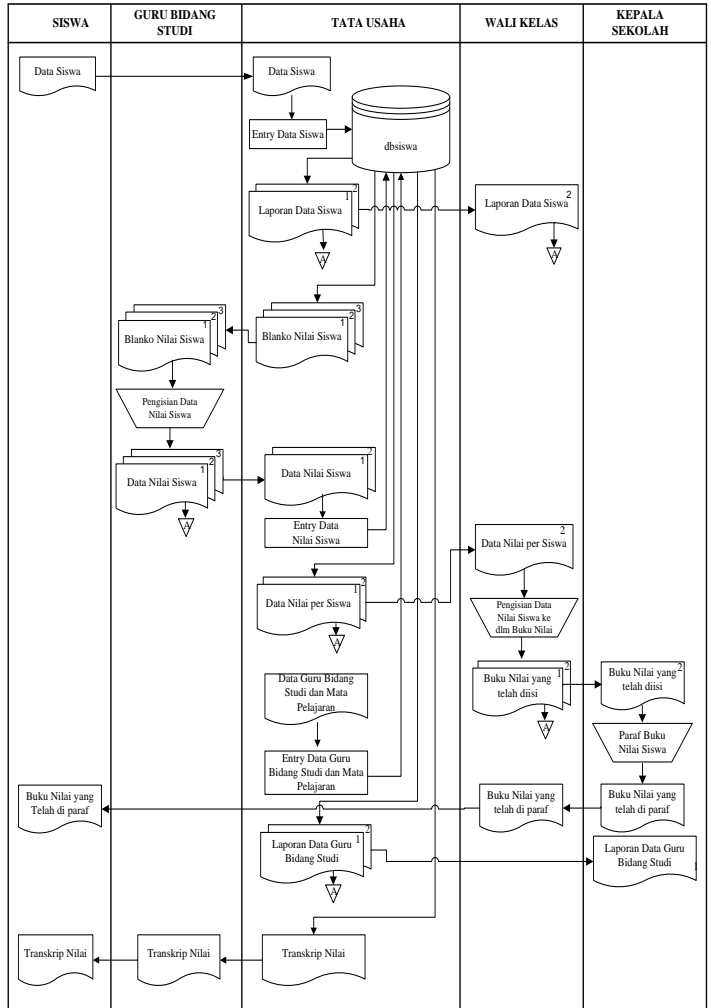

Gambar 4 Aliran Sistem Informasi Baru

\section{c. Context Diagram}

Context Diagram adalah diagram aliran data yang selalu mengandung satu proses saja (seringkali diberi nama proses 0 ), proses ini mewakili proses seluruh sistem, berikut ini dapat dilihat gambar Context Diagram.

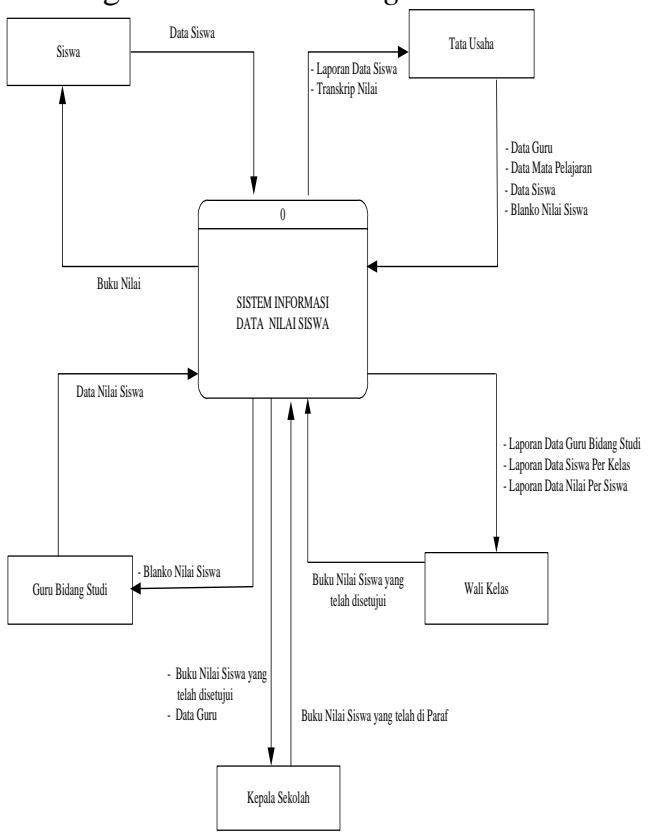

Gambar 5 Context Diagram

\section{d. Data Flow Diagram}

Data Flow Diagram level 0 merupakan penjabaran dari Context Diagram seperti dapat dilihat pada gambar 6 dibawah ini.

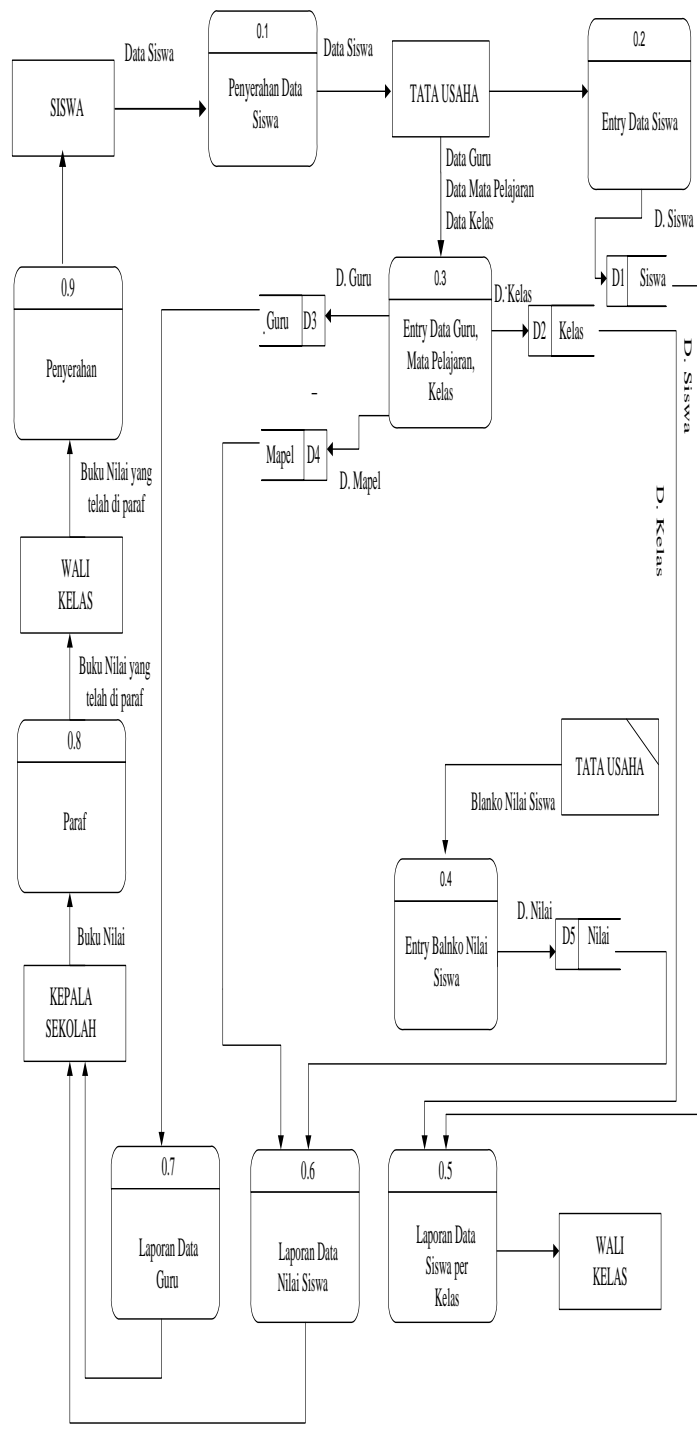

\section{Gambar 6 Data Flow Diagram}

\section{e. Entity Relationship Diagram}

Agar proses pembuatan sistem bisa berjalan dengan baik, perlu adanya kerangka data atau database dari aplikasi yang akan di buat. ERD memberikan gambaran bahwa dalam sebuah database terdiri dari tabel-tabel yang saling berhubungan antara tabel satu dengan tabel lainnya. 
IN F ORMA T I K A

Jurnal Informatika, Manajemen dan Komputer, Vol.11 No.2, Desember 2019

eISSN : 2580-3042

pISSN : 1979-0694

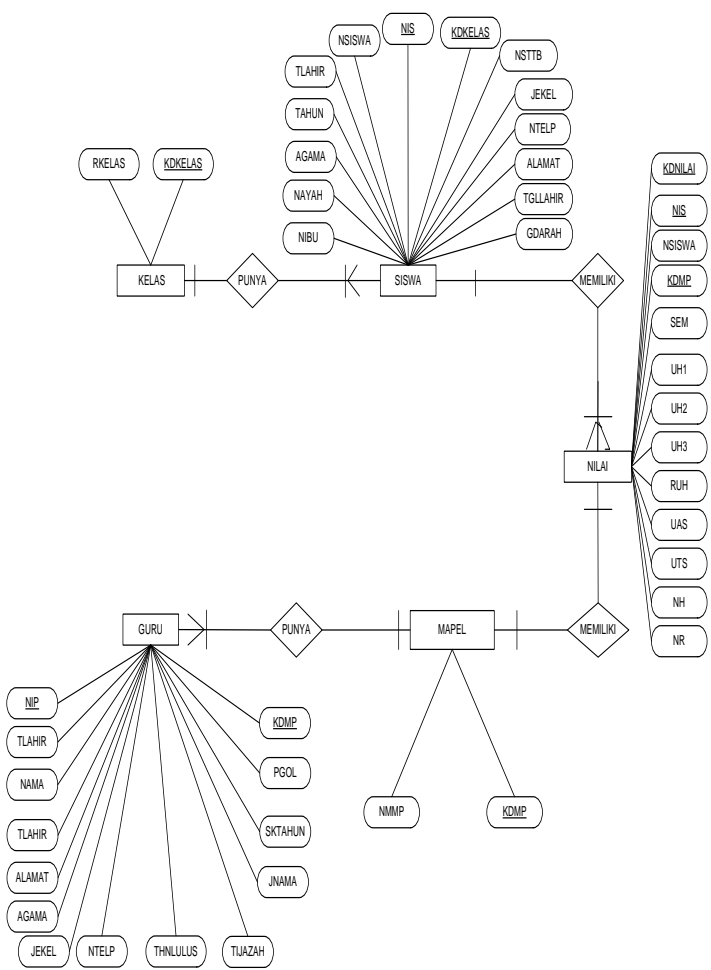

Gambar 7 Entity Relationship Diagram

\section{f. Implementasi Program}

\section{Menu Utama.}

Form Menu Utama merupakan form yang muncul bila pengguna berhasil melakukan login dengan benar, pada form menu utama terdapat empat buah sub menu program, yaitu Menu Entry Data, Proses, Laporan dan Exit seperti yang dapat dilihat pada gambar 7 berikut ini:

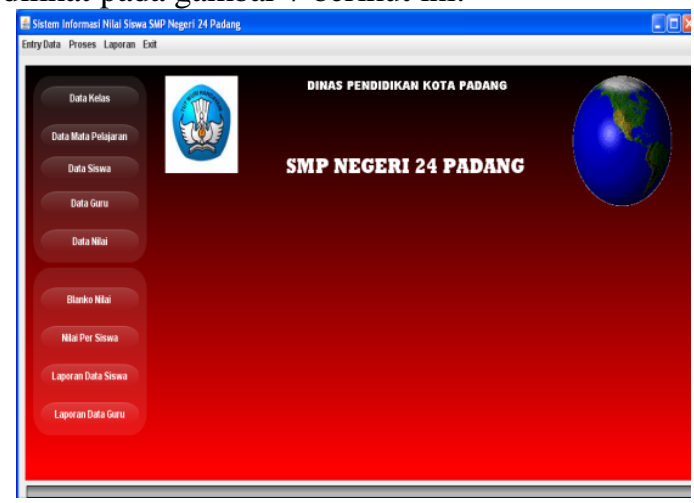

Gambar 8 Menu Utama

\section{Menu Entri Data Kelas}

Entri data kelas berguna untuk menyimpan data kelas dan nantinya memudahkan pembuatan laporan siswa per kelas serta agar dalam entri data siswa user mudah memilih kelas yang diinginkan. Berikut ini tampilan Entri data kelas

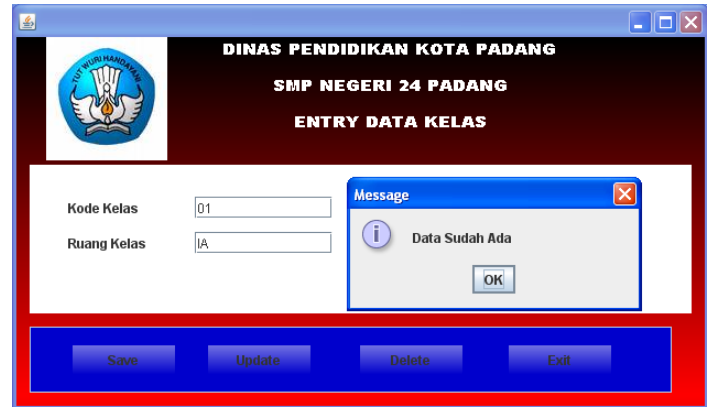

Gambar 9 Menu Entry Data Kelas

3. Menu Entri Data Mata Pelajaran

Form entri mata pelajaran nantinya menjadi tabel yang akan memproses proses entri nilai, dan menjadi tabel penting dalam proses pengolahan data nilai ini. Berikut ini tampilan entri mata pelajaran yang sudah di buat.

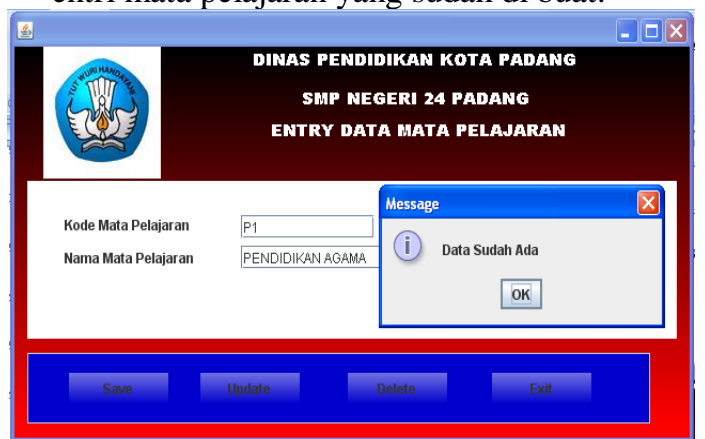

Gambar 10 Menu Entry Data Mata Pelajaran

\section{Menu Entri Data Siswa}

Entri siswa merupakan file master di dalam sistem informasi yang kita buat, untuk itu perlu diperhatikan field-field yang akan kita tampilkan di menu entri data siswa ini. Agar lebih jelas, perhatikan gambar 11 berikut ini.

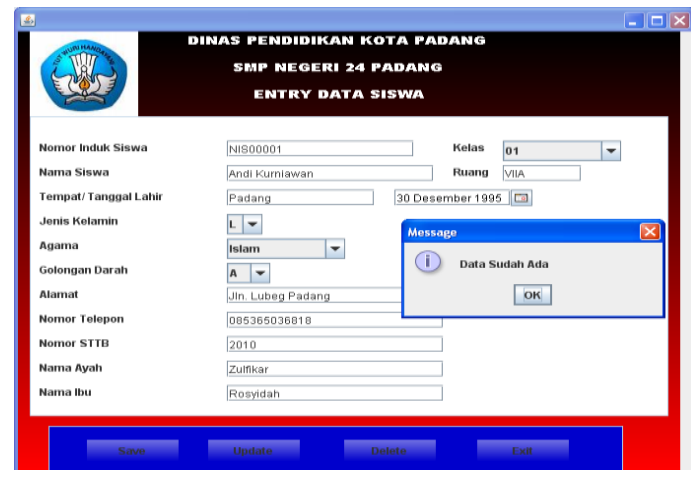

Gambar 11 Menu Entry Data Siswa

\section{Menu Entri Data Guru}

Form guru terdiri dari beberapa field, seperti NIP, Nama guru yang mengajar serta field lainnya. Hal ini berguna agar menjadi masukan dan informasi tentang data diri dari 
IN F ORMA T I K A

Jurnal Informatika, Manajemen dan Komputer, Vol.11 No.2, Desember 2019

eISSN : 2580-3042

pISSN : 1979-0694

guru yang mengajar di SMP Negeri 24

Padang saat sekarang ini.

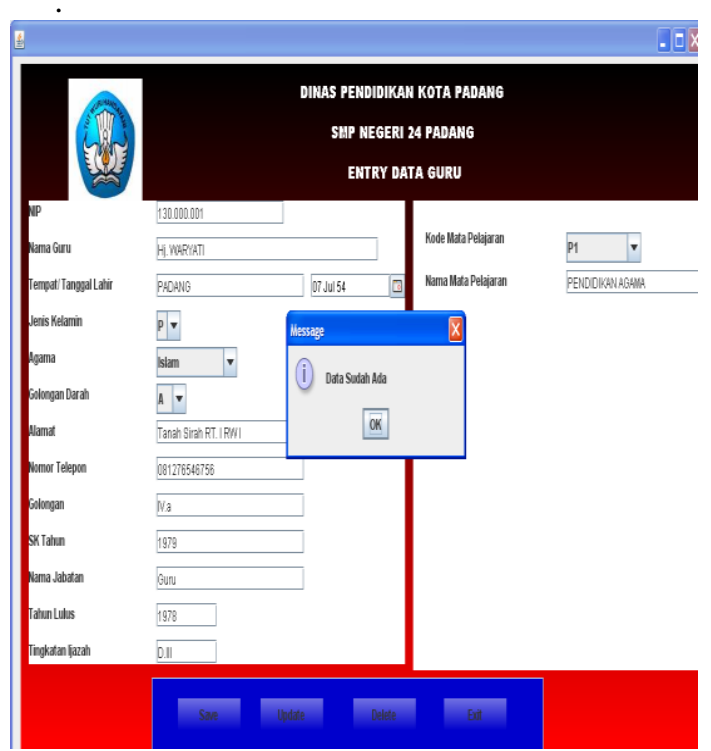

Gambar 12 Menu Entry Data Siswa

\section{Menu Proses Data Nilai}

Proses entri nilai merupakan pemanggilan dari tabel-tabel yang sudah ada. seperti tabel siswa, guru dan mata pelajaran. Dari proses input nilai ini nantinya akan di hasilkan laporan nilai siswa keseluruhan dan per siswa.

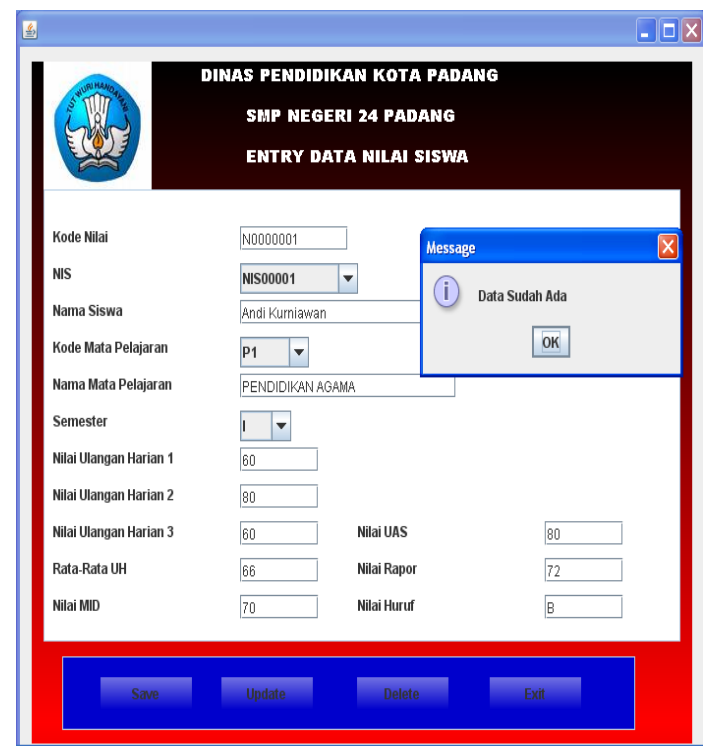

Gambar 13 Menu Proses Data Nilai

\section{Menu Laporan Blanko Nilai Siswa}

Blanko nilai siswa merupakan tampilan nilai seluruh siswa, blanko nilai akan menampilkan nilai masing-masing siswa di dalam form yang sama.

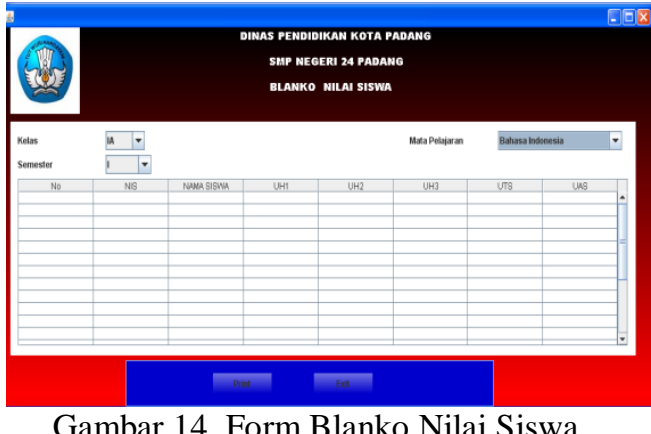

Gambar 14 Form Blanko Nilai Siswa

8. Menu Laporan Nilai Per Siswa

Laporan nilai ini di dapat dari tabel nilai, siswa, guru dan mata pelajaran. Laporan ini menjelaskan secara detail nilai dari masingmasing siswa.

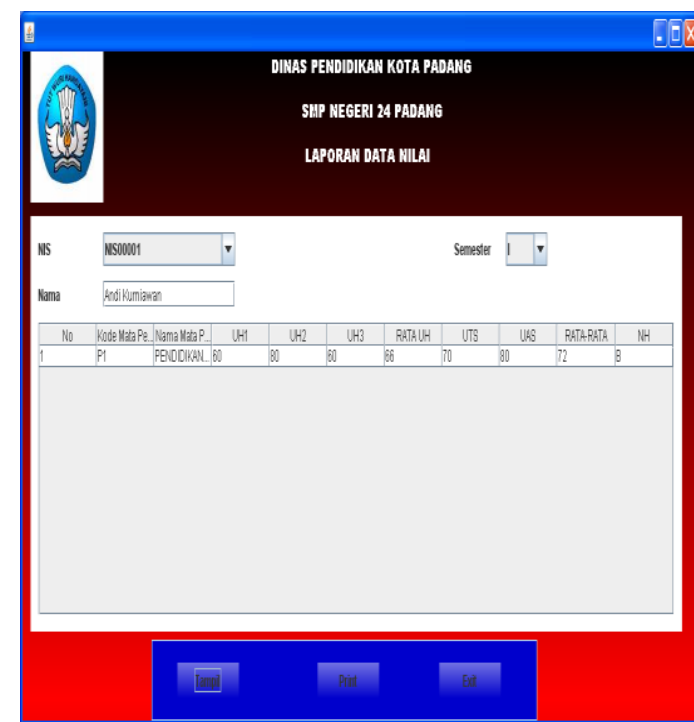

Gambar 15 Form Laporan Nilai Per Siswa

\section{KESIMPULAN}

Kesimpulan yang penulis dapatkan dalam penelitian ini antara lain :

1. Sistem informasi akademik (nilai) ini mampu mengolah data dalam jumlah besar dengan waktu yang lebih singkat dan meningkatkan efisiensi waktu operator system.

2. Dengan adanya sistem informasi ini, sekolah dapat bersaing dengan sekolah lain yang terlebih dahulu menggunakan sistem informasi akademik ini.

3. Dengan memanfaatkan Database MySQL, akan lebih mudah mencari data lampau yang suatu saat di butuhkan. 
IN F ORMA TIK

Jurnal Informatika, Manajemen dan Komputer, Vol.11 No.2, Desember 2019

eISSN : 2580-3042

pISSN : 1979-0694

\section{REFERENSI}

Ayu, I. G., \& Saryanti, D. (2018). Perancangan Sistem Informasi Cuti Karyawan Berbasis Website Menggunakan Framework Laravel. 374-381.

Firmansyah, Y., \& Udi, U. (2017). Penerapan Metode Sdlc Waterfall Dalam Pembuatan Sistem Informasi Akademik Berbasis Web Studi Kasus Pondok Pesantren Al-Habib Sholeh Kabupaten Kubu Raya, Kalimantan Barat. Jurnal Teknologi Dan Manajemen Informatika,

Https://Doi.Org/10.26905/Jtmi.V4i1.1605

Hakim, Ahmad, Rofiq, A., \& Cahyadi, R. A. (N.D.). Sistem Informasi Pengajuan Cuti Pegawai Negeri Sipil Daerah Kota Samarinda Berbasis Web. 8-14.

Khomsiatin, Y. L. (2007). Sistem Informasi Permohonan Cuti Karyawan.

Supratman, Defit, S., \& Vitriani. (2019). Readiness Index Of Higher Education In Implementing. 6(3), 267-276. Https://Doi.Org/10.25126/Jtiik.20196986

Yulisman. (2019). Pengembangan Sistem Informasi Akademik Untuk Pendaftaran Ujian Sidang Laporan Akhir Mahasiswa Stikes Hang Tuah Pekanbaru, Informatika 11(1).1-12.

Http://Dx.Doi.Org/10.36723/Juri.V11i1.14 8 